\title{
Naringenin inhibits migration of lung cancer cells via the inhibition of matrix metalloproteinases-2 and -9
}

\author{
HUAI-LU CHANG ${ }^{1 *}$, YUH-MING CHANG ${ }^{2,3 *}$, SHIH-CHAN LAI ${ }^{4}$, KE-MIN CHEN $^{4}$, \\ KUAN-CHU WANG ${ }^{5}$, TSU-TING CHIU ${ }^{5}$, FU-HSIN CHANG ${ }^{6,7}$ and LI-SUNG HSU ${ }^{3,8}$ \\ ${ }^{1}$ Department of Thoracic Surgery of Zouying Branch, Kaohsiung Armed Force General Hospital, Kaohsiung 81342; \\ ${ }^{2}$ Department of Neurology, Division of Internal Medicine, Hsinchu Mackay Memorial Hospital, Hsinchu 30071; \\ ${ }^{3}$ Institutes of Biochemistry, Microbiology and Immunology; ${ }^{4}$ Department of Parasitology; \\ ${ }^{5}$ School of Medical Laboratory and Biotechnology, Chung Shan Medical University, Taichung 40201; \\ ${ }^{6}$ Department of Biomedical Research, Asia-Pacific Biotech Developing, Kaohsiung 80681; \\ ${ }^{7}$ Institute of Biomedical Sciences, National Sun Yat-Sen University, Kaohsiung 804; \\ ${ }^{8}$ Clinical Laboratory, Chung Shan Medical University Hospital, Taichung 40201, Taiwan, R.O.C.
}

Received June 12, 2016; Accepted September 15, 2016

DOI: $10.3892 /$ etm.2016.3994

\begin{abstract}
Lung cancer is among the most common causes of cancer-related mortality. It has a high mortality rate and resistance to chemotherapy due to its high metastatic potential. Naringenin, a bioactive compound identified in several fruits, displays anti-inflammatory and antitumor effects. Furthermore, naringenin mitigates the migration of several human cancer cell types. However, the effects of naringenin on lung cancer remain unclear. The current study investigated the mechanisms of naringenin on the migration of lung cancer A549 cells. The results indicate that significant alteration in A549 cell proliferation was observed in response to naringenin $(0-300 \mu \mathrm{M})$ treatment for 24 and $48 \mathrm{~h}$. Furthermore, a dose-dependent migration inhibition of A549 in the presence of naringenin was observed by healing and transwell migration assays. In addition, a zymography assay revealed that naringenin exhibited a concentration-dependent inhibition of matrix metalloproteinase (MMP)-2 and -9 activities. Furthermore, naringenin also inhibited the activities of AKT in a dose-dependent manner. These observations indicated
\end{abstract}

Correspondence to: Mr. Fu-Hsin Chang, Department of Biomedical Research, Asia-Pacific Biotech Developing, 13 Western 1st Street, Kaohsiung Export Processing Zone, Kaohsiung 80681, Taiwan, R.O.C.

E-mail: bio_apd@yahoo.com.tw

Professor Li-Sung Hsu, Institutes of Biochemistry, Microbiology, and Immunology, Chung Shan Medical University, 110 Sec. 1, Jianguo North Road, Taichung 40201, Taiwan, R.O.C.

E-mail: 1shsu405@yahoo.com.tw

${ }^{*}$ Contributed equally

Key words: naringenin, migration, lung cancer that naringenin inhibited the migration of lung cancer A549 cells through several mechanisms, including the inhibition of AKT activities and reduction of MMP-2 and -9 activities.

\section{Introduction}

Chemoprevention is the administration of natural products or synthetic compounds to inhibit tumorigenesis, trigger apoptosis, or both, in tumor cells (1). However, natural chemopreventive agents, which include polyphenols, alkaloids, carotenoids, and nitrogen compounds, have little or no toxicity in normal cells (1). Flavonoids are compounds isolated from a wide range of dietary foods, including vegetables, fruit, wine and tea, and have received a attention due to their chemopreventive and chemotherapeutic activities (2). It has been revealed that flavonoids may exhibit antitumor activity against several human cancer types (2). For example, butein inhibits the migration and invasion of bladder cancer cells by reducing the expression of extracellular signal-regulated kinase $1 / 2$ and its activities (3). In addition, butein has been found to elevate reactive oxygen species (ROS) levels and trigger apoptosis in neuroblastoma (4) and breast cancer cells $(5,6)$. Moreover, shikonin induces apoptosis in osteosarcoma cells via the generation of ROS (7). In addition, shikonin triggers necrosis and apoptosis in gastric cancer cells (8). Furthermore, a bioactive compound isolated from citrus called naringenin has been revealed to trigger apoptosis and inhibit migration in cancer cells (9). Treatment with naringenin resulted in apoptosis by activation of the p38 mitogen-activated protein kinase and caspase 3 pathway in cancer cells that expressed estrogen receptor $\mathrm{a}$ or $\mathrm{b}(10)$. In addition, exposure to naringenin disrupted the mitochondrial membrane potential, decreased AKT activities, activated the caspase cascade and eventually triggered apoptosis in HTP-1 human leukemia cells (11). Similarly, naringenin caused mitochondrial dysfunction, increased the $\mathrm{Bax} / \mathrm{Bcl}-2$ ratio and as a consequence induced apoptosis in HepG2 hepatocellular cells (12). Co-treatment 
with naringenin enhanced the cytotoxic effects of tamoxifen in breast cancer cells (13). Similarly, naringenin increased tumor necrosis factor-related apoptosis-inducing ligand-induced apoptosis by elevating death receptor 5 expression in A549 lung cancer cells (14).

Lung cancer is one of the leading causes of cancer-related mortality worldwide (15). The high mortality rate of lung cancer is due to diagnostic difficulties and a high potential to metastasize (16). Thus, to improve the clinical outcome, novel agents for the inhibition of metastasis in lung cancer cells without affecting normal cells are urgently required. To the best of our knowledge the present study is the first to reveal the molecular mechanisms underlying the effects of naringenin on the migration of A549 lung cancer cells.

\section{Materials and methods}

Materials. RPMI, fetal bovine serum (FBS), penicillin and streptomycin were purchased from Invitrogen (Thermo Fisher Scientific, Inc., Waltham, MA, USA). Chemicals including naringenin, isopropanol, Triton X-100, polyacrylamide, Coomassie brilliant blue gelatin and Giemsa were obtained from Sigma-Aldrich (Merck Millipore, Darmstadt, Germany).

Cell culture. Human A549 lung cancer cells were purchased from American Type Culture Collection (Manassas, VA, USA) and maintained in RPMI supplemented with $10 \%$ FBS, $100 \mathrm{U} / \mathrm{ml}$ penicillin and $100 \mu \mathrm{g} / \mathrm{ml}$ streptomycin. The cell line was grown at $37^{\circ} \mathrm{C}$ under a humidified atmosphere with $5 \%$ $\mathrm{CO}_{2}$ to $80-90 \%$ confluence.

MTT assay. The A549 cells were seeded in 24-well plates at a density of $2 \times 10^{4} / \mathrm{ml}$ and were treated with $0,25,50,100$, 200 and $300 \mu \mathrm{M}$ naringenin for 24 and $48 \mathrm{~h}$. Following the treatment, the cells were incubated with fresh medium containing $5.0 \mathrm{~g} / 1 \mathrm{MTT}$, and incubated at $37^{\circ} \mathrm{C}$ for an additional $2 \mathrm{~h}$. After washing with PBS, the sediments were dissolved in $1 \mathrm{ml}$ isopropanol and the absorbance at $563 \mathrm{~nm}$ was determined. The relative viability rate was determined based on the absorbance at $563 \mathrm{~nm}$ of each sediment compared with vehicle-treated groups.

Western blot analysis. Naringenin-treated A549 cells were lysed in $150 \mu$ l RIPA lysis buffer (Thermo Fisher Scientific, Inc.). The lysates were centrifuged at $14,000 \mathrm{x} g$ for $10 \mathrm{~min}$ and the supernatants were collected. A Bio-Rad Protein assay kit (Bio-Rad Laboratories, Inc., Hercules, CA, USA) was used to determine the protein concentration. A total of $50 \mu \mathrm{g}$ protein per lane was separated using $10 \%$ polyacrylamide gel electrophoresis and transferred onto a nitrocellulose membrane (Merck Millipore). The membrane was blocked with PBS with $0.5 \%$ non-fat milk for $1 \mathrm{~h}$ at room temperature. After washing with PBS containing 0.1\% Tween-20 (PBST), the membrane was incubated with phospho-AKT (1:500 dilution; cat. no. sc-16646; Santa Cruz Biotechnology, Inc., Dallas, TX, USA), total-AKT (1:500 dilution; cat. no. sc-8312; Santa Cruz Biotechnology, Inc.) or $\beta$-actin (1:1,000 dilution; cat. no. sc-47778; Santa Cruz Biotechnology, Inc.) primary antibodies at $4^{\circ} \mathrm{C}$ overnight. The membrane was then washed with PBST and reacted with horseradish peroxidase-conjugated secondary antibody (1:5,000 dilution; sc-2005; Santa Cruz Biotechnology, Inc., Dallas, TX, USA) at room temperature for $1 \mathrm{~h}$. Following extensivel washing with PBST, the positive signal was determined by enhanced chemiluminescence (GE Healthcare Life Sciences, Chalfont, UK) and $\beta$-actin expression was used as an internal control. The results were quantified using Fujifilm Multi Gauge version 3.0 software (Fujifilm, Tokyo, Japan).

Wound healing assay. For the wound healing assays, cells were seeded at a density of $1 \times 10^{6} / \mathrm{ml}$. A wound was created by scraping the cell monolayer with a sterilized tip. After removing the detached cells, the cells were treated with the indicated concentration of naringenin for 24 or $48 \mathrm{~h}$. The migrations were counted by detecting the cell numbers in the cell-free regions. The value is represented the as mean \pm standard deviation of three independent experiments.

Gelatin zymography assay. Cells were incubated in serum-free medium and treated with the indicated naringenin concentration for $24 \mathrm{~h}$. Conditional medium was obtained and separated using $8 \%$ sodium dodecyl sulfate-polyacrylamide gel containing $0.1 \%$ gelatin. The gel was washed with washing buffer $(2.5 \%$ Triton X-100) twice with gentle agitation at room temperature for $30 \mathrm{~min}$ and incubated with reaction buffer [40 mM Tris- $\mathrm{HCl}$ (pH 8.0), $10 \mathrm{mM} \mathrm{CaCl}_{2}, 0.01 \% \mathrm{NaN}_{3}$ ] for $12 \mathrm{~h}$ at $37^{\circ} \mathrm{C}$. The gel was then stained with Coomassie brilliant blue R250. The degraded zones represented the matrix metalloproteinase (MMP)-2 and -9 activities.

Migration assay. Cells were treated with different concentrations of naringenin for $24 \mathrm{~h}$ and seeded at a density of $5 \times 10^{5} / \mathrm{ml}$ in the upper chamber of the 48 -well Boyden chamber (Merck Millipore). The lower chamber contained 20\% FBS. Next, the chamber was incubated at $37^{\circ} \mathrm{C}$ for $24 \mathrm{~h}$ and the cells that migrated to the lower surface of the membrane were fixed in methanol for $10 \mathrm{~min}$ and stained with $10 \%$ Giemsa for $1 \mathrm{~h}$.

Reverse transcription-polymerase chain reaction (RT-PCR). A549 cells were treated with various concentrations of naringenin for $24 \mathrm{~h}$. Total RNA was extracted using TRIzol reagent (Invitrogen; Thermo Fisher Scientific, Inc.), according to the manufacturer's protocol. Total RNA $(3 \mu \mathrm{g})$ was reverse transcribed to first strand cDNA using a Script Reverse Transcription System (Promega Corporation, Madison, WI, USA). Primers (Protech Technology Corporation, Taipei, Taiwan) for MMP-2 and -9 were designed as MMP-2 forward: 5'-CTCAGATCCGTGGTGAGATCT-3' and reverse: 5'-CTT TGGTTCTCCAGCTTCAGG-3'. MMP-9 forward: 5'-ATC CAGTTTGGTGTCGCGGAGC-3' and reverse: 5'-GAAGGG GAAGACGCACAGCT-3'. PCR was performed in a $10 \mathrm{ml}$ reaction volume contained 0.5 units DreamTaq polymerase (Thermo Fisher Scientific, Inc.), $1 \mu \mathrm{l}$ reaction buffer (Thermo Fisher Scientific, Inc.), $1 \mu \mathrm{l} \mathrm{cDNA,} 0.1 \mu \mathrm{M}$ forward and reverse primer, $0.2 \mathrm{mM} \mathrm{dNTP}$ and $4.9 \mu \mathrm{l}$ water. The PCR conditions were the following: 35 cycles of denaturation at $94^{\circ} \mathrm{C}$ for $1 \mathrm{~min}$, annealing at $60^{\circ} \mathrm{C}$ for $1 \mathrm{~min}$ and polymerization at $72^{\circ} \mathrm{C}$ for $1 \mathrm{~min}$. The PCR fragments were separated using a $2 \%$ agarose gel and stained with ethidium bromide and $\beta$-actin was used as an internal control. 


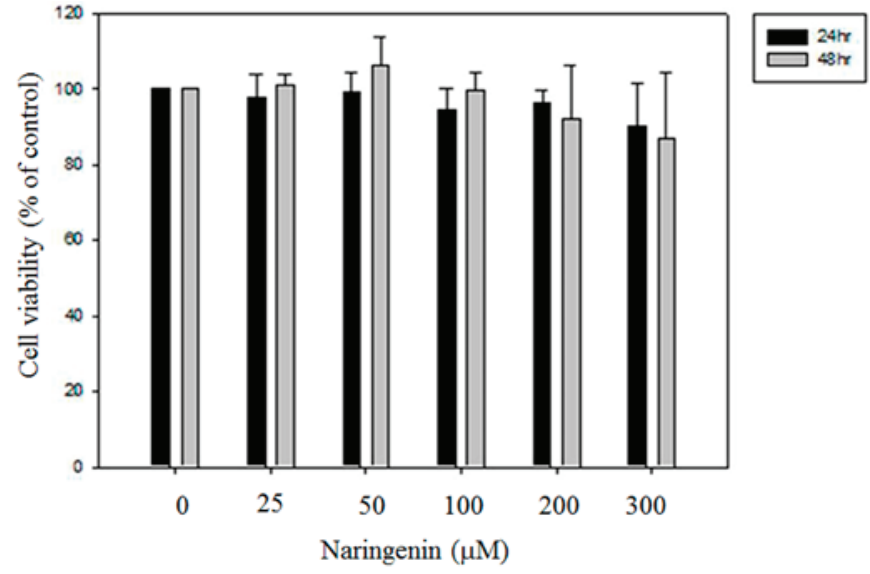

Figure 1. Effects of naringenin on the cell viability of lung A549 cells. A549 cells were treated with $0,25,50,100,200$ and $300 \mu \mathrm{M}$ naringenin for 24 or $48 \mathrm{~h}$. The cell viability was then measured using an MTT assay. Data are presented as the mean \pm standard deviation obtained from at least three independent experiments.

Statistical analysis. Data are represented as the mean \pm standard deviation of three independent experiments and were evaluated by Student's t-test using SPSS 14.0 software (SPSS, Inc., Chicago, IL, USA). $\mathrm{P}<0.05$ was used to indicate a statistically significant difference.

\section{Results}

Naringenin has no effect on the proliferation of A549 lung cancer cells. To address whether naringenin affected the proliferation of lung cancer cells, we have treated A549 cells were treated with different concentrations of naringenin. As shown in Fig. 1, the cell viability was $100,97.54 \pm 6.21,99.36 \pm 4.95$, $94.25 \pm 5.88,96.13 \pm 3.60$ and $90.39 \pm 11.06 \%$ in the presence of $0,25,50,100,200$ and $300 \mu \mathrm{M}$ naringenin for $24 \mathrm{~h}$ and $100,101.26 \pm 2.77,106.26 \pm 7.41,99.70 \pm 4.77,92.12 \pm 14.24$ and $87.09 \pm 17.29 \%$ for $48 \mathrm{~h}$, respectively. The results indicated that naringenin did not influence the proliferation of lung cancer A549 cells.

Naringenin reduces the migration of A549 lung cancer cells. To investigate the effects of naringenin on the migration of A549 cells, wound healing and Boyden chamber assays were performed. Exposure to 100, 200 and $300 \mathrm{mM}$ naringenin for $24 \mathrm{~h}$ slightly decreased the motility of A549 cells. Furthermore, treatment with 200 and $300 \mu \mathrm{M}$ naringenin for 48 h significantly inhibited the migration of A549 cells and as a consequence reduced the cell number in the wound zones compared with vehicle-treated group (Fig. 2). To further confirm the inhibitory effects of migration of naringenin on A549 cells, a Boyden chamber assay was conducted. As shown in Fig. 3, in the presence of naringenin, the migration of A549 cells was significantly lower than in the vesicle-treated group.

Naringenin significantly inhibits MMP-2 and -9 activities. Degradation of the extracellular matrix by MMPs is important in cell migration, and in order to investigate whether naringenin reduced the MMP-2 and -9 activities, two major MMPs responsible for cancer migration were studied by

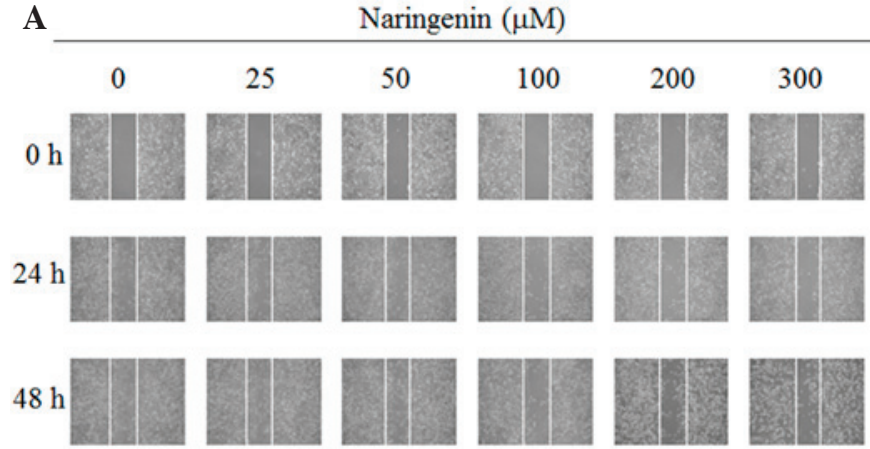

B

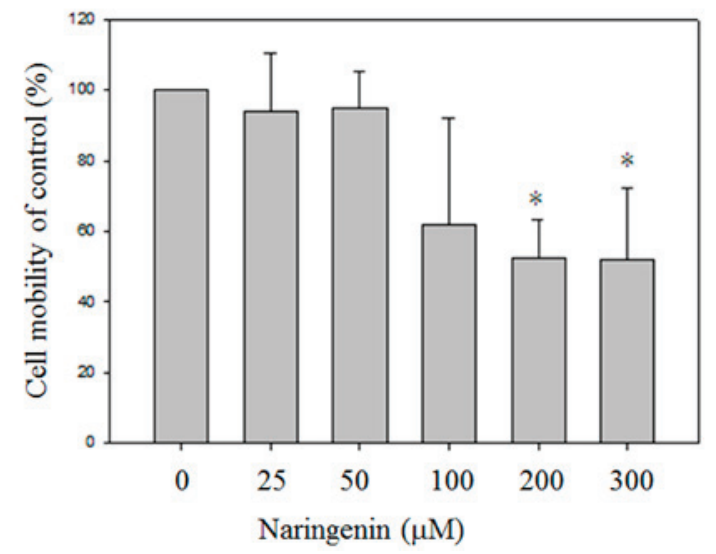

Figure 2. Naringenin inhibited the cell mobility of A549 cells in a dose-dependent manner. (A) For the wound healing assay, A549 monolayer cells were scratched by pipette tips, followed by treatment with the indicated concentration of naringenin for 24 and $48 \mathrm{~h}$. The images were captured under a phase contract microscope (magnification, x100). (B) Data are presented as the mean \pm standard deviation obtained from at least three independent experiments. The cell mobility of the control was set to $100 \%$. ${ }^{*} \mathrm{P}<0.05$ vs. control group.

zymography. Naringenin significantly inhibited MMP-2 and -9 activities in proportion to the treated concentration (Fig. 4A). To further investigate whether naringenin affected the expression of MMP-2 and -9, RT-PCR was performed. As shown in Fig. 4B, no overt alternation of MMP-2 and -9 expression was identified in the cells in response to naringenin treatment.

Naringenin inhibits AKT activities. A previous report has shown that naringenin attenuated AKT activities in bladder cancer cells. In order to test whether naringenin also inhibited AKT activities, western blot analysis was performed. The phosphorylation of the AKT/total AKT ratio was 90.7, 90.0, $81.0,83.2$ and $76.5 \%$ when exposed to $25,50,100,200$ and $300 \mu \mathrm{M}$ naringenin compared to the vehicle-treated group (Fig. 5). Furthermore, no evident alternation of nuclear factor

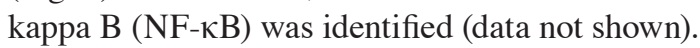

\section{Discussion}

Lung cancer is of high prevalence and mortality worldwide. Metastasis and drug resistance are the two major functions contributing to poor survival and prognosis of lung cancer (16). However, natural products such as naringenin have been shown to exhibit antiproliferation effects. $(12,14)$ In the present study, 
A

\begin{tabular}{|c|c|c|c|c|c|}
\hline \multicolumn{6}{|c|}{ Naringenin $(\mu \mathrm{M})$} \\
\hline 0 & 25 & 50 & 100 & 200 & 300 \\
\hline
\end{tabular}

B

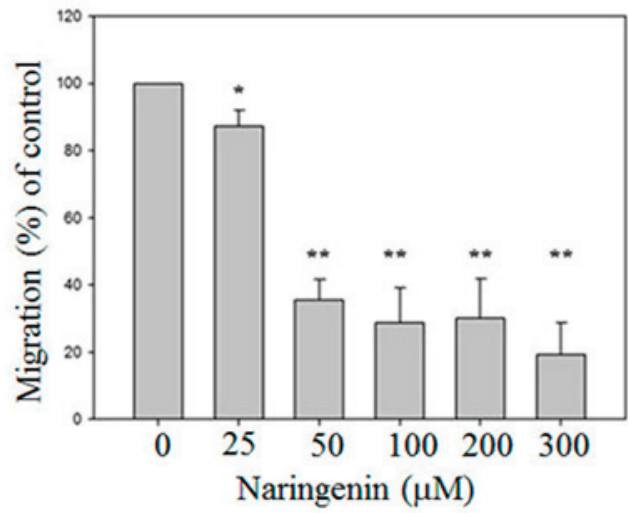

Figure 3. Naringenin reduced the migration of A549 cells. The cells were treated with different concentrations of naringenin as described in Materials and methods. (A) Migrated cells were stained with Giemsa and images were captured under a phase contract microscope (magnification, x100). (B) Data are represented as the mean \pm standard deviation obtained from at least three independent experiments. The migration of the control was set to $100 \%$. ${ }^{*}<0.05$ and ${ }^{* *} \mathrm{P}<0.001$ vs. control group.

A

\begin{tabular}{|c|c|c|c|c|c|}
\hline \multicolumn{6}{|c|}{ Naringenin $(\mu \mathrm{M})$} \\
\hline 0 & 25 & 50 & 100 & 200 & 300 \\
\hline
\end{tabular}
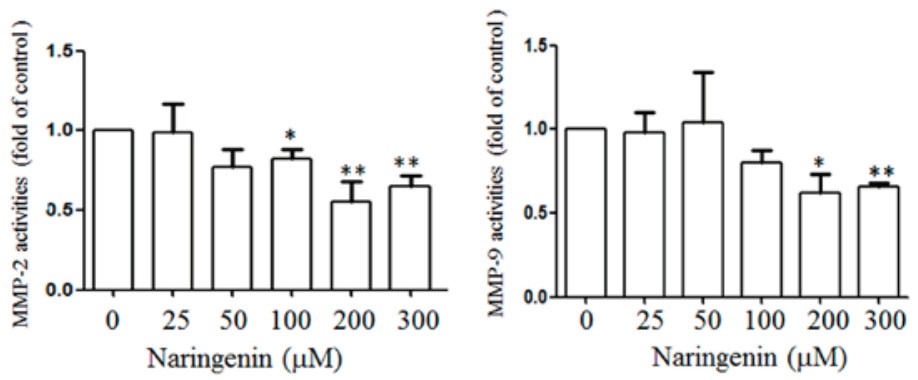

B

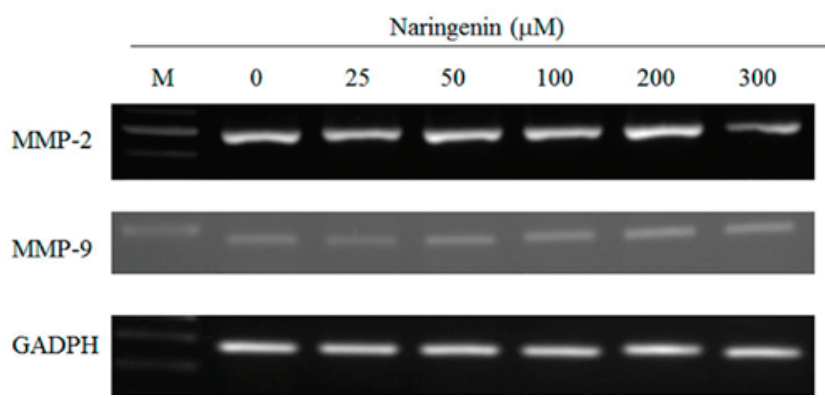

Figure 4. Effect of naringenin on the MMP-2/MMP-9 activity and the expression of A549 cells. (A) A549 cells were treated with the indicated concentration of naringenin for $24 \mathrm{~h}$. Conditional mediums were collected and MMP-2 and -9 activities were determined by gelatin zymography analysis. Lower panel: Data are presented as the mean \pm standard deviation obtained from at least three independent experiments. The activity of the control was set to 1 . "P<0.05 and ${ }^{* *} \mathrm{P}<0.001$ vs. control group ( $0 \mu \mathrm{M}$ naringen). (B) RT-PCR analysis of MMP-2 and -9 expression. A549 cells were treated with naringenin for $24 \mathrm{~h}$ and the total RNA was extracted. The expression of MMP-2 and -9 was detected using a PCR assay using a 100 bp marker (in lane M). MMP, matrix metalloproteinase; GAPDH, glyceraldehyde 3-phosphate dehydrogenase; RT-PCR, reverse transcription-polymerase chain reaction. 
A

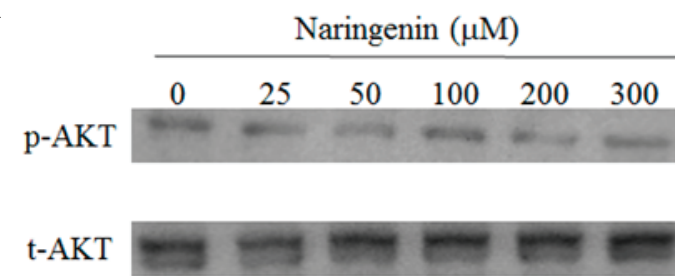

$\beta$-actin

B

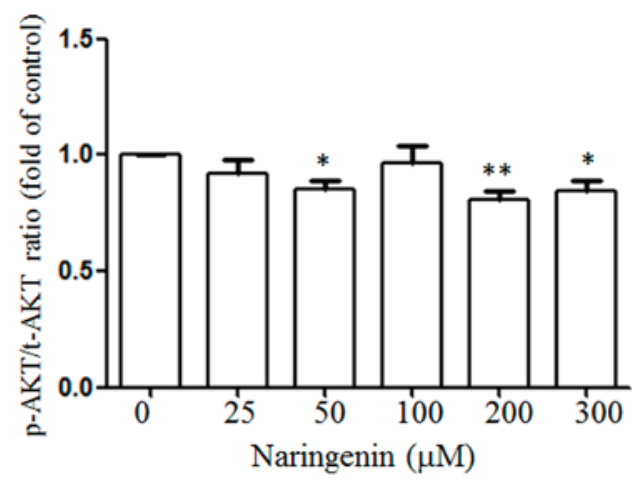

Figure 5. Naringenin attenuated AKT activities of A549 cells. (A) Total cell lysates obtained from cells were treated with the indicated concentration of naringenin for $48 \mathrm{~h}$ and were subjected to western blot analysis using the antibody indicated. $\beta$-actin was included as an internal control. (B) Data are presented as the mean \pm standard deviation obtained from at least three independent experiments. The ratio of the control was set to 1 . ${ }^{~} \mathrm{P}<0.05$ and ${ }^{* *} \mathrm{P}<0.001$ vs. control group. $\mathrm{P}$, phospho; t, total.

the effects of naringenin on cell migration of lung cancer cells were investigated. The results demonstrated that naringenin diminished the activities of MMP-2 and -9, inhibited AKT activity and as a consequence reduced the migration of lung cancer cells.

During metastasis, tumor cells can secret enzymes, predominantly MMPs, to degrade the extracellular cell matrix and to facilitate cancer cell invasion into the blood or lymph vessels and circulate to other sites (17). Prior results have shown that elevated MMP-2 and -9 was observed in late stages of cancer, which could be a prognostic factor in several human cancers (17). Furthermore, prevention of lung cancer metastasis by inhibition of MMP-2 and/or MMP-9 by bioactive compounds isolated from plants and herbs has been previously demonstrated $(18,19)$. Extracts from Antrodia cinnamomea displayed antimetastatic effects by the supersession of MMP-2 and -9 activities $(18,19)$. Furthermore, fisetin and myricetin inhibited the nuclear translocation of NF- $\mathrm{KB}, \mathrm{c}-\mathrm{Fos}$ and c-Jun, decreased the expression and activities of MMP-2 and urokinase-type plasminogen activator, and eventually attenuated the migration and metastasis of lung A549 cells $(20,21)$. In line with these observations, naringenin was presently shown to reduce the activities of MMP-2 and -9 as evidenced by zymography analysis and then inhibited the migration of lung A549 cells.

It is well known that the AKT pathway is involved in cell proliferation and migration. Activation of AKT triggered the translocation of NF- $\mathrm{KB}$ from the cytosol to the nucleus, then enhanced the expression of MMP-9 (22). However, it blocked the activities of AKT by wortmannin and also suppressed MMP-2 expression (23). Previous reports have demonstrated that polyphenol isolated from vegetables and fruits inhibited lung cancer migration through the reduction of the AKT activity $(24,25)$. Extracts from Ecklonia cava that were enriched in polyphenol suppress the migration of lung A549 cells via the downregulation of AKT and MMP-2 activities (25). In addition, licochalcone A attenuated the migration of lung A549 cells by the downregulation of the AKT activity and suppression of the MMP-1 and -3 expression (24). In the present study, treatment with naringenin reduced the phosphorylation of AKT in a dose-dependent manner. In line with the present observations, Liao et al (26) demonstrated that naringenin attenuated the migration of bladder cancer cells via the inhibition of AKT activities. Overall, naringenin reduced the activity of AKT and subsequently inhibited the migration of lung A549 cells.

In summary, the observations of the present study provided the first evidence that naringenin inhibits lung cancer migration via the suppression of AKT activity and the downregulation of MMP-2 and -9.

\section{Acknowledgements}

The present study was supported by grants obtained from the Ministry of Science and Technology of Taiwan (grant no. MOST-103-2311-B-040-001) and from Chung Shan Medical University (grant no. CSMU-INT-104-02).

\section{References}

1. Kotecha R, Takami A and Espinoza JL: Dietary phytochemicals and cancer chemoprevention: A review of the clinical evidence. Oncotarget: May 25, 2016 (Epub ahead of print). doi: 10.18632/ oncotarget.9593.

2. Stagos D, Amoutzias GD, Matakos A, Spyrou A, Tsatsakis AM and Kouretas D: Chemoprevention of liver cancer by plant polyphenols. Food Chem Toxicol 50: 2155-2170, 2012.

3. Zhang L, Chen W and Li X: A novel anticancer effect of butein: Inhibition of invasion through the ERK1/2 and NF-kappa B signaling pathways in bladder cancer cells. FEBS Lett 582: 1821-1828, 2008.

4. Chen YH, Yeh CW, Lo HC, Su SL, Hseu YC and Hsu LS: Generation of reactive oxygen species mediates butein-induced apoptosis in neuroblastoma cells. Oncol Rep 27: 1233-1237, 2012.

5. Cho SG, Woo SM and Ko SG: Butein suppresses breast cancer growth by reducing a production of intracellular reactive oxygen species. J Exp Clin Cancer Res 33: 51, 2014.

6. Yang LH, Ho YJ, Lin JF, Yeh CW, Kao SH and Hsu LS: Butein inhibits the proliferation of breast cancer cells through generation of reactive oxygen species and modulation of ERK and p38 activities. Mol Med Rep 6: 1126-1132, 2012.

7. Chang IC, Huang YJ, Chiang TI, Yeh CW and Hsu LS: Shikonin induces apoptosis through reactive oxygen species/extracellular signal-regulated kinase pathway in osteosarcoma cells. Biol Pharm Bull 33: 816-824, 2010.

8. Lee MJ, Kao SH, Hunag JE, Sheu GT, Yeh CW, Hseu YC, Wang CJ and Hsu LS: Shikonin time-dependently induced necrosis or apoptosis in gastric cancer cells via generation of reactive oxygen species. Chem Biol Interact 211: 44-53, 2014.

9. Mir IA and Tiku AB: Chemopreventive and therapeutic potential of 'naringenin', a flavanone present in citrus fruits. Nutr Cancer 67: 27-42, 2015.

10. Totta P, Acconcia F, Leone S, Cardillo I and Marino M: Mechanisms of naringenin-induced apoptotic cascade in cancer cells: Involvement of estrogen receptor alpha and beta signalling. IUBMB Life 56: 491-499, 2004.

11. Park JH, Jin CY, Lee BK, Kim GY, Choi YH and Jeong YK: Naringenin induces apoptosis through downregulation of Akt and caspase- 3 activation in human leukemia THP-1 cells. Food Chem Toxicol 46: 3684-3690, 2008. 
12. Arul D and Subramanian P: Naringenin (citrus flavonone) induces growth inhibition, cell cycle arrest and apoptosis in human hepatocellular carcinoma cells. Pathol Oncol Res 19: 763-770, 2013.

13. Hatkevich T, Ramos J, Santos-Sanchez I and Patel YM: A naringenin-tamoxifen combination impairs cell proliferation and survival of MCF-7 breast cancer cells. Exp Cell Res 327: 331-339, 2014.

14. Jin CY, Park C, Lee JH, Chung KT, Kwon TK, Kim GY, Choi BT and Choi YH: Naringenin-induced apoptosis is attenuated by Bcl-2 but restored by the small molecule Bcl-2 inhibitor HA 14-1, in human leukemia U937 cells. Toxicol In Vitro 23: 259-265, 2009.

15. Jemal A, Murray T, Ward E, Samuels A, Tiwari RC, Ghafoor A, Feuer EJ and Thun MJ: Cancer statistics, 2005. CA Cancer J Clin 55: 10-30, 2005.

16. Sangodkar J, Katz S, Melville H and Narla G: Lung adenocarcinoma: Lessons in translation from bench to bedside. Mt Sinai J Med 77: 597-605, 2010.

17. Itoh $\mathrm{Y}$ and Nagase $\mathrm{H}$ : Matrix metalloproteinases in cancer. Essays Biochem 38: 21-36, 2002.

18. Chen YY, Chou PY, Chien YC, Wu CH, Wu TS and Sheu MJ: Ethanol extracts of fruiting bodies of Antrodia cinnamomea exhibit anti-migration action in human adenocarcinoma CL1-0 cells through the MAPK and PI3K/AKT signaling pathways. Phytomedicine 19: 768-778, 2012.

19. Chen YY, Liu FC, Chou PY, Chien YC, Chang WS, Huang GJ, $\mathrm{Wu} \mathrm{CH}$ and Sheu MJ: Ethanol extracts of fruiting bodies of Antrodia cinnamomea suppress CL1-5 human lung adenocarcinoma cells migration by inhibiting matrix metalloproteinase-2/9 through ERK, JNK, p38, and PI3K/Akt signaling pathways. Evid Based Complement Alternat Med 2012: 378415, 2012.
20. Liao YC, Shih YW, Chao CH, Lee XY and Chiang TA: Involvement of the ERK signaling pathway in fisetin reduces invasion and migration in the human lung cancer cell line A549. J Agric Food Chem 57: 8933-8941, 2009.

21. Shih YW, Wu PF, Lee YC, Shi MD and Chiang TA: Myricetin suppresses invasion and migration of human lung adenocarcinoma A549 cells: Possible mediation by blocking the ERK signaling pathway. J Agric Food Chem 57: 3490-3499, 2009.

22. Reuben PM and Cheung HS: Regulation of matrix metalloproteinase (MMP) gene expression by protein kinases. Front Biosci 11: 1199-1215, 2006.

23. Bradley JM, Kelley MJ, Rose A and Acott TS: Signaling pathways used in trabecular matrix metalloproteinase response to mechanical stretch. Invest Ophthalmol Vis Sci 44: 5174-5181, 2003.

24. Huang HC, Tsai LL, Tsai JP, Hsieh SC, Yang SF, Hsueh JT and Hsieh YH: Licochalcone A inhibits the migration and invasion of human lung cancer cells via inactivation of the Akt signaling pathway with downregulation of MMP-1/-3 expression. Tumour Biol 35: 12139-12149, 2014

25. Lee H, Kang C, Jung ES, Kim JS and Kim E: Antimetastatic activity of polyphenol-rich extract of Ecklonia cava through the inhibition of the Akt pathway in A549 human lung cancer cells. Food Chem 127: 1229-1236, 2011.

26. Liao AC, Kuo CC, Huang YC, Yeh CW, Hseu YC, Liu JY and Hsu LS: Naringenin inhibits migration of bladder cancer cells through downregulation of AKT and MMP-2. Mol Med Rep 10: 1531-1536, 2014. 